\title{
HISTOPATHOLOGICAL REVIEW OF MESENTERIC AND OMENTAL CYSTS IN CHILDREN
}

M. Ramani ${ }^{1}$, Kazi Wajid Husain ${ }^{2}$, O.H. Radhika Krishna ${ }^{3}$, Ramesh Reddy4, P. Sreenivasa Reddy5, D. Pradeep Kumar6, G. Sunitha7.

1. Professor. Department Of Pathology, Niloufer Hospital, Hyderabad.

2. Post Graduate, Department Of Pathology, Niloufer Hospital, Hyderabad.

3. Assistant Professor, Department Of Pathology, Niloufer Hospital, Hyderabad.

4. Professor \& H.O.D, Department Of Paediatric Surgery, Niloufer Hospital, Hyderabad.

5. Professor, Department Of Paediatric Surgery, Niloufer Hospital, Hyderabad.

6. III rd. Year, Undergraduate, Osmania Medical College, Hyderabad.

7. Post Graduate, Department Of Pathology, Niloufer Hospital, Hyderabad.

\section{CORRESPONDING AUTHOR:}

M. Ramani, Niloufer Hospital, Red Hills, Hyderabad, Andhra Pradesh.

E-mail: drmramani@sify.com

\section{HOW TO CITE THIS ARTICLE:}

M. Ramani, Kazi Wajid Husain, O.H. Radhika Krishna, Ramesh Reddy, P. Sreenivasa. Reddy, D. Pradeep Kumar, G. Sunitha, "Histopathological Review of Mesenteric and Omental Cysts in Children." Journal of Evolution of Medical and Dental Sciences 2013; Vol2, Issue 26, July 1; Page: 4701-4709.

ABSTRACT: BACKGROUND: Cystic lesions of the mesentery are uncommon lesions which are infrequently diagnosed prior to surgery. They may be located anywhere in gastrointestinal tract, although they are most often found in small bowel mesentery. Mesenteric and omental cysts are unique for their diverse clinical presentation, etiology, radiological features and pathological characteristics. AIMS AND OBJECTIVES: To present a series of patients with mesenteric and omental cysts, their clinical presentation, gross \& histopathology with special emphasis on new updated classification proposed by Marc de Perrot in 2000. MATERIAL AND METHODS: A total of 5376 surgical specimens in Paediatric Referral Hospital , Hyderabad from June 2003 to May 2012 of which 55 children presented with mesenteric and omental cysts, which were prospectively and retrospectively evaluated. Gross, radiologic images and histopathological sections were reviewed to categorize and classify, to determine their relationship to mesentery and intestines.

RESULTS: The study group comprised of 39 boys and 16 girls with an age range of 3 days to 7 years. There was male predominance with $\mathrm{M}$ : $\mathrm{F}=2.4: 1$. CONCLUSION: Mesenteric and omental cysts in children are rare benign lesions but present with huge masses and acute symptoms very early in their lives. Preoperative diagnosis and localization are very difficult. Histopathological classification of mesenteric and omental cysts has an advantage of identifying epithelial lining and distinguishing malignant masses that possess a cystic appearance and aid in post-operative chemotherapy or radiotherapy.

KEYWORDS: Mesenteric cysts, Omental cysts, Marc de Perrot classification, Children. 
INTRODUCTION: Mesenteric and omental cysts are rare benign intra-abdominal tumours occurring in approximately one of 100,000 hospitalized patients and one in every 20,000 pediatric patients [1]. Only $2.2 \%$ of these cysts are diagnosed as omental cysts. These cysts are stated to be more common in females than in males .The omental cysts are rarer, with only about 150 cases documented till date, $25 \%$ of which presented in children under 10 years of age [2].They may be located anywhere in gastrointestinal tract, although they are most often found in mesentery of the small bowel[3].

Mesenteric and omental cysts are unique for their diverse clinical presentation, etiology, radiological features, and pathological characteristics. Initial classification proposed by Beahrs et al (1950). (Table 1) recognized four categories of mesenteric and omental cysts, it has now been categorized into six types by the updated classification by Marc de Perrot (2000) [4]

This study is based on clinical presentation, gross features and histopathology of the patients with mesenteric and omental cysts with a special emphasis on new updated classification suggested by Marc de Perrot.

MATERIALS AND METHODS: The present study was undertaken at Department of Pathology, Paediatric Referral Hospital, Hyderabad. This retrospective and prospective study was conducted from June 2003 to May 2012. During this period, a total of 5376 surgical specimens were received, of which 55 cases were diagnosed as enteric cysts of abdomen, 39 were males and 16 females. All 55 cases were categorized based on clinical data, radiological findings and histopathological examination. After routine processing, sections from all the cases were stained with Haematoxylin and Eosin. Based on histopathological examination all 55 cases were further classified into various subtypes based on the updated classification recommended by Marc de Perrot (Table 2).

OBSERVATIONS AND RESULT: The study group comprised of 39 boys and 16 girls with an age range of 3 days to 7 years. There was male predominance with $\mathrm{M}: \mathrm{F}=2.4: 1$.The most common presentation was abdominal distension followed by mass abdomen, pain abdomen and acute intestinal obstruction. The commonest sites included the small bowel mesentery, sigmoid mesocolon and retroperitoneum (Chart 1).

After classifying mesenteric and omental cysts histopathologically (Table 3) we found that in this present study only 6 cases were diagnosed as omental cysts in comparison to 49 cases of mesenteric cysts, indicating that omental cysts are rarer than mesenteric cysts .Out of 55 cases, 25 presented with Pseudocysts. All the cases were benign with no evidence of malignancy. Most of the cyst walls were composed of fibrocollagenous tissue showing no lining, few of them showed columnar or cuboidal to flat endothelial lining. (Figure 2, 3 and 5)

Grossly the mesenteric (Figure 1) and omental cysts showed grey brown to tan white surface. Most cysts were multi-loculated with few of them being unilocular, with average size ranging from 2 to $16 \mathrm{~cm}$. One of the omental cyst grossly showed mullerian remnants (Figure 4)

DISCUSSION: Mesenteric and omental cysts are benign, may be unilocular or multilocular and these are endothelial-lined cysts. Mesenteric cysts are located in the mesentery of jejunum, ileum and rarely mesocolon. Both are considered to have a similar pathogenetic mechanism [5]. The well accepted theory, suggested by Gross, is benign proliferation of ectopic lymphatics in the mesentery 
that absence of communication with the rest of the lymphatic system [6]. Mesenteric and omental cysts could cause acute abdomen from cyst rupture, infection, hemorrhage, volvulus and extrinsic compression. In general, these acute symptoms are more common in children than adults [7].

The first report of a mesenteric cyst is commonly ascribed to a Florentine anatomist, Beneviene, who related the finding of a cyst of the small bowel mesentery during an autopsy in 1507. The first surgical excision was reported in 1880 by Tillaux, and since that time numerous case reports have been reported. Loeb reviewed the literature on mesenteric cysts in 1941. Presently there are about 700-750 cases reported in the literature. Omental cysts were not described until the report of Gairdner in 1852, and are less common than the mesenteric variety.

Mesenteric cysts have been estimated to be three to ten times more common than omental cysts, on this basis, the ratio is 4.5 to 1 . These lesions are generally reported to be more common in females than in males. About $60 \%$ of these cysts occur before the age of 5 years, but they can also found in adults. These lesions can be located anywhere along the gastrointestinal tract; however, those associated with the small intestine are more frequent. Common symptoms include abdominal pain, abdominal distention, anemia, anorexia, weight loss and intestinal obstruction, but it is a rare cause for mass abdomen. Pain may be secondary to bleeding, infection, torsion. Very rarely, mesenteric cysts undergo malignant transformation. Histologically, mesenteric cysts are benign cystic proliferations of lymphatic tissue; however, they typically do not communicate with the lymphatic system. Apart from ascites, the differential diagnosis of omental cysts include cystic lesions such as choledochal cysts, splenic cysts, pancreatic cysts and cystadenomas, multicystic dysplastic kidney, gastrointestinal duplication cysts, and ovarian cysts ${ }^{[8]}$.

Mesenteric cyst must be differentiated from gastrointestinal duplications. Duplications have common blood supply, intimately associated with bowel wall, and contains well defined muscular wall [9]. In contrast, mesenteric cyst has an endothelial lining, less vascular, thin wall [10].

In our series, the age range of our patients was 3 days to 8 years. There is a male preponderance in our studies in contrast to studies done by Chang et al.(2011)[11] and Jane et al. (2009) [12]which showed female preponderance (Table 4).

Our series shows 55 patients, during 9-year period from 2003 to 2012.The incidence is approximately 1 in 10,000 admissions, higher compared to available world literature. Majority of the cysts in our study were located in small intestine with the results similar to the studies done by chang et al (2011) [11]. According to Jane et al (2009) the most common location of the cysts was retroperitoneum (Table 4) [12].

Most cysts are unilocular, but few cases are multi locular. Average size ranged from 2 to $16 \mathrm{~cm}$. Most cysts are lined with a single layer of columnar or cuboidal epithelial cells (Figure 2 and 3). This layer is sometimes destroyed as a result of pressure exerted by the cyst fluid. (Figure 5)

Chang et al. (2011) ${ }^{[11]}$ reported three cases of omental cyst while Jane et al. (2009) ${ }^{[12]}$ reported six cases of omental cyst which was higher. Our study showed similar results in comparison with the study of Chang et al.

We compared our studies with available literature to determine the incidence of malignancy in mesenteric and omental cysts. In our study there were no cases with malignancy which has similar results in comparison to the available literature. Studies done by Chang et al (2011) [11], Walker et al (1973) [13].O'Brien et al (1999) [14]., and Chen et al (2011) [15] showed no incidence of any malignancy in mesenteric and omental cysts. In contrast the study done by Jane et 
al. (2009) [12] reported three cases of malignancy. Cysts of the secondary Mullerian system have a known risk of malignant transformation. (Table 5)

The most common physical finding of a mesenteric cyst is a compressible abdominal mass, movable transversely but not longitudinally. Cysts of omental origin are usually freely movable.

The diagnostic features of clinically significant omental and mesenteric cysts appear to be a function of size, location, and presence or absence of complicating factors such as hemorrhage, torsion, infection, rupture or pressure on adjacent structures.

Ultrasonography is now considered essential in the diagnosis of omental cysts. They may remain asymptomatic in most of the cases, but they can grow to great proportions with reported cases of cysts containing over three liters of fluid[16].The preferred treatment of omental cyst is complete excision. Bowel resection is rarely necessary and recurrence is rare [6].

CONCLUSION: Mesenteric and omental cysts in children are rare benign lesions but they present with huge masses and acute symptoms very early in their lives. Preoperative diagnosis and localization remains challenging. Histopathological classification of mesenteric and omental cysts has the advantage of identifying epithelial lining and distinguishing malignant masses that possess a cystic appearance and aid in post-operative Chemotherapy or Radiotherapy.

\section{REFERENCES}

1. Goyal S, Verma RK, Singh SP, Ahsan MM. Mesenteric Cyst of Transverse Mesocolon: A Rare Case Report and Review of Literature. Arch Clin Exp Surg. Online First: 21 Jul, 2012.

2. Motie, Mohammad Reza, and Mehdi Asadi. "Large Omental Cyst: A Case Report and Review of the Literature." Acta Medica Iranica 49.10 (2011): 690-693.

3. Se Ik Kim, Young Dae Kim, Hye Seung Lee, Byung Chul Jee.A Case Of Mesenteric Cyst Confused With Ovarian Endometrioma. Korean J Obstet Gynecol 2012; 55(9):683-686.

4. de Perrot M, Brundler M, Totsch M, Mentha G, Morel P. Mesenteric cysts. Towardless confusion? Digestive Surgery. 2000; 17(4):323-8.

5. J. CatTey. Mesentery and Omentum. Pediatric X-Ray Diagnosis 1973. 574-575.

6. Prakash A, Agrawal A, Gupta RK, Sanghvi B, Parelkar S. Early management of mesenteric cyst prevents catastrophes: A single centre analysis of 17 cases. Afr J Paediatr Surg 2010; 7:140-3.

7. Vanek VW, Phillips AK. Retroperitoneal, mesenteric, and omental cysts. Archives of Surgery. 1984 July; $119(7): 838-842$.

8. Wootton-Gorges SL, Thomas KB, Harned RK, Wu SR, Stein-Wexler R, Strain JD. Giant cystic abdominal masses in children. Pediatric Radiology. 2005 December: 35(12):1277-88.

9. Otto S. Steinreich. The Diagnosis of Mesenteric Cysts. Annals of Surgery. 1955 November; 142(5): 889-894.

10. Scully RE, Galdabini JJ, Mc Neely BU: Case records of the Massachusetts General Hospital. New England Journal of Medicine 298:558-563, 1988.

11. Chang TS, Ricketts R, Abramowsky CR, Cotter BD, Steelman CK, Husain A, ShehataBM. Mesenteric cystic masses: a series of 21 pediatric cases and review of the literature. Fetal Pediatric Pathology. 2011; 30(1):40-4. 
12. Tan JJ, Tan KK, Chew SP. Mesenteric cysts: an institution experience over 14years and review of literature. World Journal of Surgery.2009 September; 33(9):1961-5.

13. Walker AR, Putnam TC. Omental, mesenteric, and retroperitoneal cysts: a clinical study of 33 new cases. Annals of Surgery. 1973 July; 178(1):13-9.

14. O'Brien MF, Winter DC, Lee G, Fitzgerald EJ, O'Sullivan GC. Mesenteric cysts-a series of six cases with a review of the literature. Irish Journal of Medical Sciences. 1999 OctoberDecember; 168(4):233-6.

15. Chen HP, Liu WY, Tang YM, Ma BY, Xu B, Yang G, Wang XJ. Chylous mesentericcysts in children. Surgery Today. 2011 March; 41(3):358-62.

16. Rattan KN, Budhiraja S, Pandit SK, Yadav RK. Huge omental cyst mimicking ascites. Indian Journal of Pediatrics. 1996, September-October; 63(5):707-708.

Table 1: Initial classification of mesenteric and omental cyst by Beahrs

\begin{tabular}{|l|}
\hline Old Classification by Beahrs \\
\hline Developmental \\
\hline Traumatic \\
\hline Neoplastic \\
\hline Infectious \\
\hline
\end{tabular}

Table 2: New Updated Classification by Marc De Perrot (2000)

\begin{tabular}{|l|l|}
\hline 1.Cysts of lymphatic origin & a)Simple lymphatic cysts \\
\cline { 2 - 2 } & b)Lymphangiomas \\
\hline 2.Cysts of mesothelial origin & \multirow{2}{*}{ a)Simple mesothelial cysts } \\
\cline { 2 - 2 } & b)Benign cystic mesotheliomas \\
\hline \multirow{2}{*}{ 3.Cysts of enteric origin } & c)Malignant cystic mesotheliomas \\
\hline & a)Enteric duplication cysts \\
\hline 4.Cysts of urogenital origin & \\
\hline 5.Mature cystic teratomas & \\
\hline 6.Non pancreatic pseudocysts & a)Cysts of traumatic origin \\
\hline & \\
\hline
\end{tabular}


Table 3: Classification of mesenteric and omental cysts in our study histopathologically according to updated classification recommended by Marc de Perrot.

\begin{tabular}{|c|c|c|c|}
\hline Cyst type & $\begin{array}{l}\text { No of } \\
\text { cases } \\
\mathrm{N}=55\end{array}$ & Grossly & Microscopy \\
\hline $\begin{array}{l}\text { Simple lymphatic } \\
\text { cyst(chylous cyst, } \\
\text { lymphocele) }\end{array}$ & 06 & $\begin{array}{l}\text { Small }(1-5 \mathrm{~cm}) \text {, } \\
\text { unilocular, } \\
\text { thin-walled }\end{array}$ & $\begin{array}{l}\text { Lining: flat endothelial cells. } \\
\text { Wall: smooth muscle fibers, } \\
\text { lymphoid aggregates }\end{array}$ \\
\hline Lymphangioma & 07 & $\begin{array}{l}\text { Large }(>5 \mathrm{~cm}) \text {, multilocular } \\
\text { or multiple }\end{array}$ & Same as lymphocele \\
\hline $\begin{array}{l}\text { Enteric duplication } \\
\text { Cyst }\end{array}$ & 06 & $\begin{array}{l}\text { Mostly unilocular, } \\
\text { Some multilocular; } \\
\text { Small bowel mesentery }\end{array}$ & $\begin{array}{l}\text { Lining: enteric Mucosa. } \\
\text { Wall: muscular layer with } \\
\text { nervous plexus }\end{array}$ \\
\hline Enteric cyst & 08 & $\begin{array}{l}\text { Unilocular, of } \\
\text { Mesentery and mesocolon }\end{array}$ & $\begin{array}{l}\text { Lining: enteric Mucosa. } \\
\text { Wall: connective tissue Only }\end{array}$ \\
\hline $\begin{array}{l}\text { Embryonic vestigial } \\
\text { Urogenital cyst }\end{array}$ & 02 & $\begin{array}{l}\text { Variable size, } \\
\text { unilocular, multilocular }\end{array}$ & $\begin{array}{l}\text { Wolffian or Mullerian } \\
\text { Duct remnants }\end{array}$ \\
\hline $\begin{array}{l}\text { Mature cystic } \\
\text { Teratomas }\end{array}$ & 01 & Has solid areas & $\begin{array}{l}\text { Admixture of benign ectoderm, } \\
\text { endoderm and mesoderm. }\end{array}$ \\
\hline $\begin{array}{l}\text { Non-Pancreatic } \\
\text { Pseudocysts }\end{array}$ & 25 & $\begin{array}{l}\text { Variable size, } \\
\text { Thick walled, unilocular } \\
\text { and multilocular }\end{array}$ & $\begin{array}{l}\text { No epithelial lining. } \\
\text { Thick fibrous wall }\end{array}$ \\
\hline
\end{tabular}

Table 4: Comparison of clinico pathological parameters of our study with available literature.

\begin{tabular}{|c|c|c|c|}
\hline Particulars & $\begin{array}{l}\text { JANE et al. (2009) }{ }^{[12]} \\
\mathrm{N}=16 \\
\text { (ADULTS) }\end{array}$ & $\begin{array}{l}\text { CHANG et al. (2011) }{ }^{[11]} \\
\mathrm{N}=21 \\
\text { (CHILDREN) }\end{array}$ & $\begin{array}{l}\text { PRESENT STUDY } \\
\mathrm{N}=55 \\
\text { (CHILDREN) }\end{array}$ \\
\hline Study period & 1994-2007 14 years & $1965-200945$ years & 2003-2012 9 years \\
\hline $\mathrm{M}: \mathrm{F}$ & $7: 9$ & $10: 11$ & $39: 16$ \\
\hline$\overline{\text { Age }}$ & $12-68$ years & Newborn-12 years & Newborn-7 years \\
\hline Nature & 80\%Unilocular & 80\%Unilocular & 40\% Unilocular \\
\hline Omental cyst & 2Cases & 3Cases & 6 Cases \\
\hline$\overline{\text { Size }}$ & $4 \mathrm{~cm}$ to $29 \mathrm{~cm}$ & $7 \mathrm{cmto} 29 \mathrm{~cm}$ & $2 \mathrm{~cm}$ to $16 \mathrm{~cm}$ \\
\hline Location & 70\% Retroperitoneum & $70 \%$ Small bowel & $80 \%$ Small bowel \\
\hline Clinical presentation & Abdominal pain & Abdominal mass & Abdominal distension \\
\hline Malignant & 3Cases & None & None \\
\hline
\end{tabular}




\section{ORIGINAL ARTICLE}

Table 5: Comparison of benign and malignant cases by different authors and the present study.

\begin{tabular}{|l|l|l|l|l|}
\hline Authors & Study period & Benign & Malignant & Total cases \\
\hline Walker et al. (1973) [13] & 15 years & 33 & 0 & 33 \\
\hline O'brien et al. (1999) [14] & 10 years & 6 & 0 & 6 \\
\hline Jane et al. (2009) [12] & 14 years & 12 & 3 & 15 \\
\hline Chang et al. (2011) [11] & 45 years & 21 & 0 & 21 \\
\hline $\begin{array}{l}\text { Chen et al. (2011) [15] } \\
\text { Present study }\end{array}$ & 23 years & 10 & 0 & 10 \\
\hline (Children) & 09 years & 55 & 0 & 55 \\
\hline
\end{tabular}

\section{PHOTOGRAPHS}
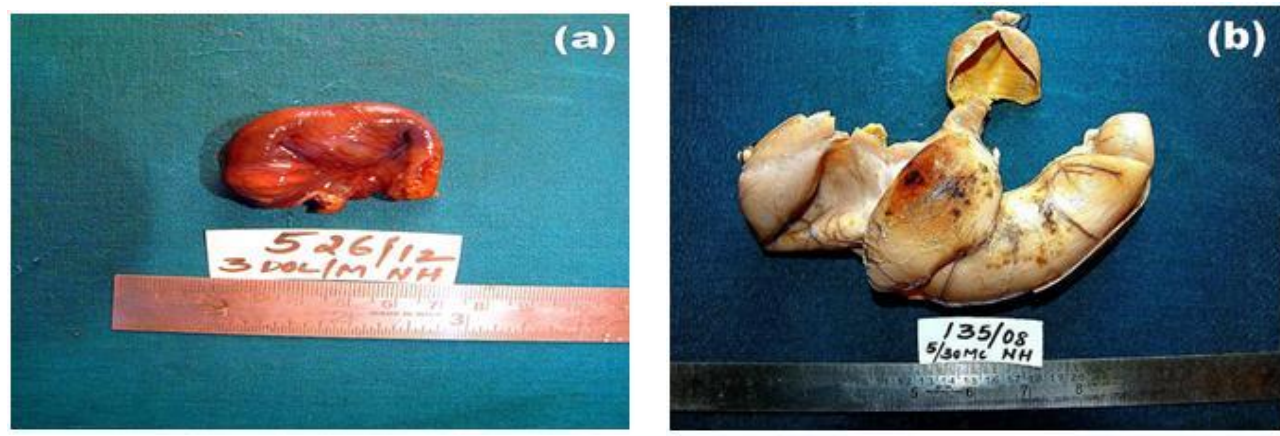

Figure 1: Gross-a) Specimen of mesenteric cyst grey brown in colour of $4 \times 3 \mathrm{cms}$. b) Large mesenteric cyst with grey tan to grey white appearance.
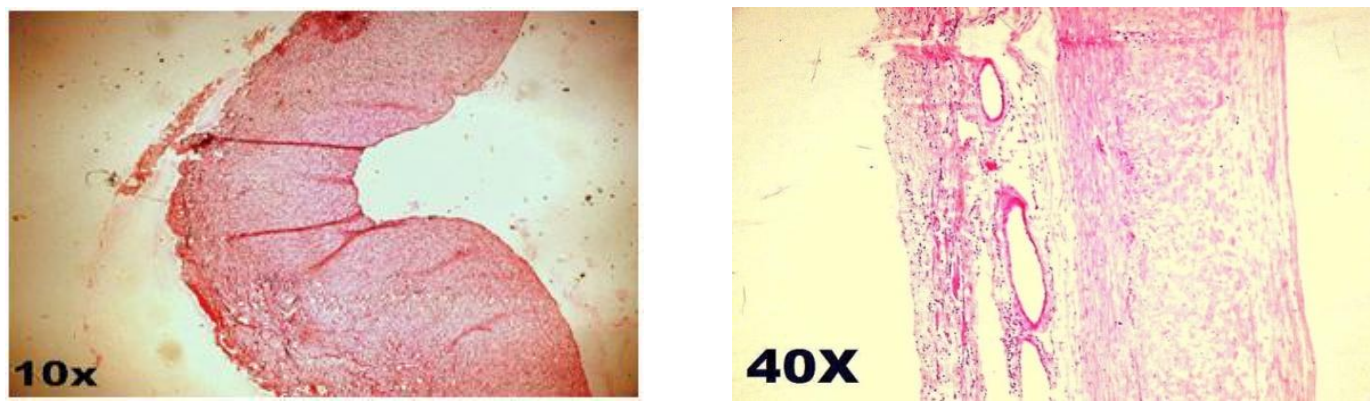

Figure 2: Haematoxylin and eosin sections of the mesenteric cysts consisting of epithelial lining and sub epithelial tissue. 


\section{ORIGINAL ARTICLE}

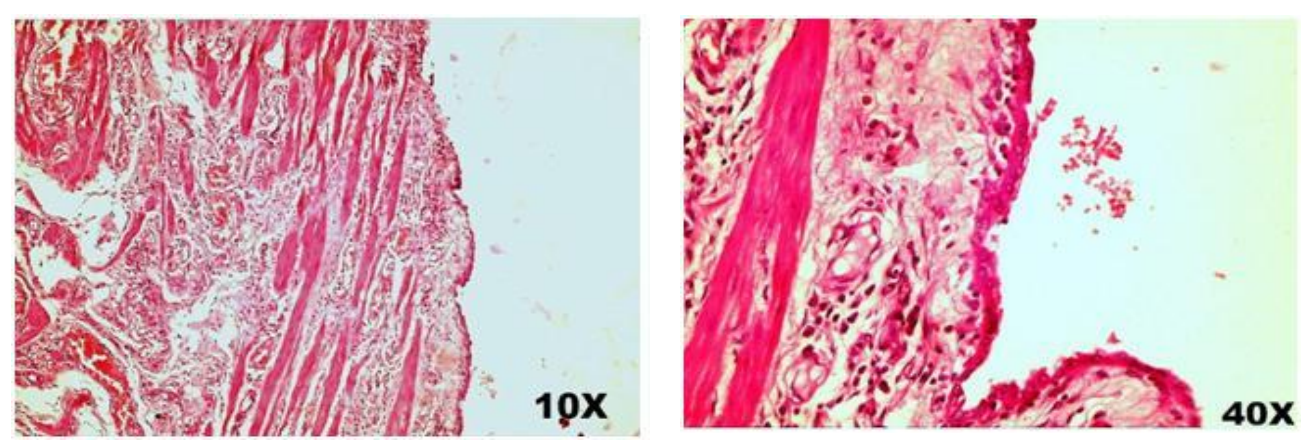

Figure 3: Haematoxylin and eosin sections of the mesenteric cysts lined by low cuboidal epithelium.
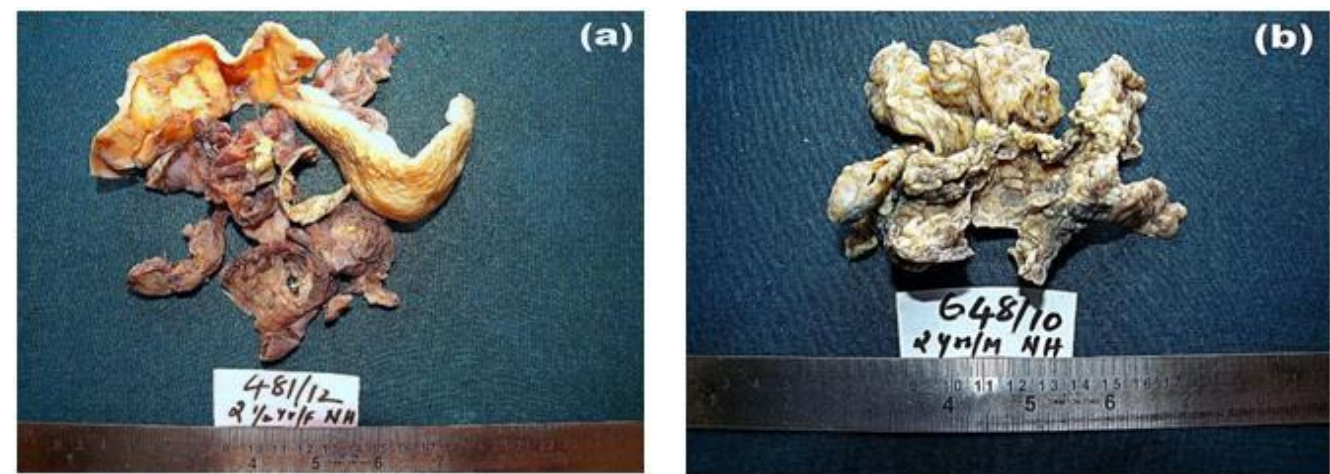

Figure 4: Gross specimens of omental cyst with adjacent mullerian tissue remnants.
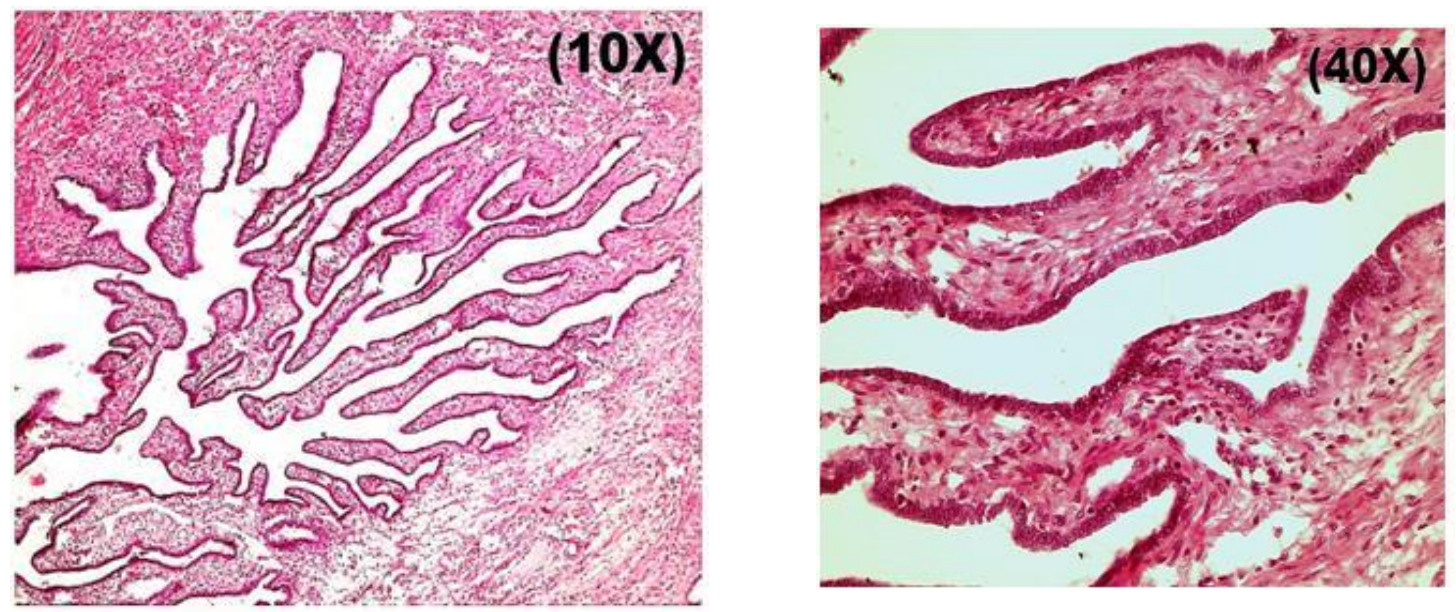

Figure5: Haematoxylin and eosin section of omental cysts lined by low cuboidal to flattened epithelium. 


\section{ORIGINAL ARTICLE}

\section{CHART}

\section{LOCATION OF CYSTS}

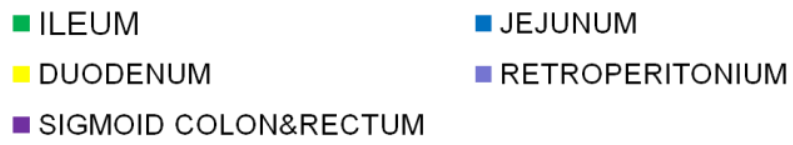

Chart 1:

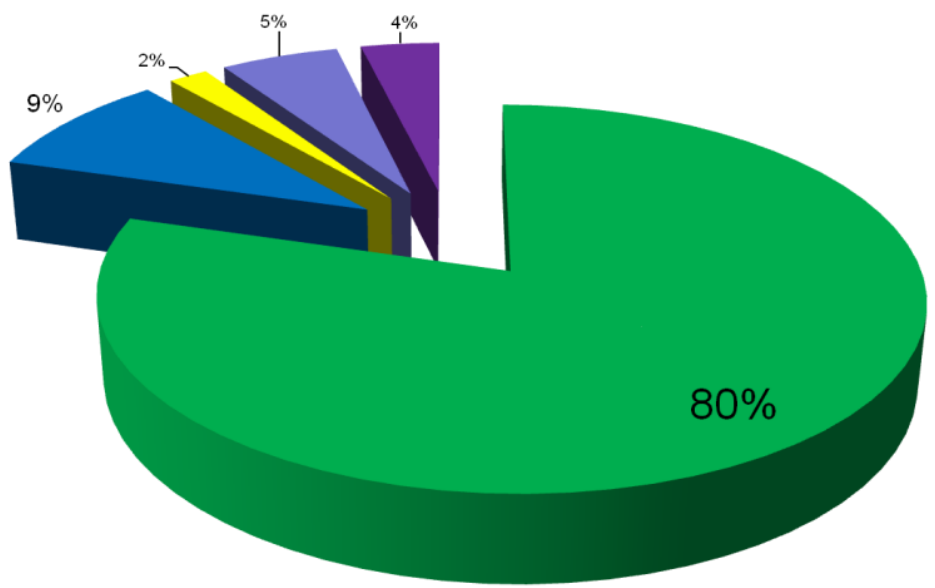

Location of the Mesenteric and omental cysts 